\title{
Pesquisa e Implementação de Programas de Educação Ambiental em ONGs: o Caso do IPÊ - Instituto de Pesquisas Ecológicas
}

\author{
Suzana M. Padua e Maria das Graças de Souza \\ Instituto de Pesquisas Ecológicas
}

Resumo: As Organizações Não Governamentais (ONGs) vêm adotando caminhos inovadores e ousados no campo da educação ambiental. Este trabalho analisa algumas razões desse processo e descreve o exemplo de uma ONG brasileira, o IPE - Instituto de Pesquisas Ecológicas, que desde a sua fundação tem na educação um de seus principais pilares. A evolução da educação ambiental dentro da própria instituição é também analisada, assim como as metodologias desenvolvidas.

Palavras-chave: Educação Ambiental. Organizações Não Governamentais. Participação. Metodologias em Educação Ambiental.

Abstract: Non-Governmental Organizations (NGOs) have been adopting daring venues in the field of environmental education. This paper analyzes some reasons why this process occurs, and describes the example of a Brazilian NGO, IPE - Instituto de Pesquisas Ecológicas (Institute for Ecological Research), which, since its foundation, has environmental education as one of its main pillars. The evolution of environmental education within the institution itself is also analyzed, as are the methodologies developed.

Keywords: Environmental Education. Non-Governamental Organizations. Participation. Methods in Environmental Education. 


\section{Introdução}

As organizações não governamentais (ONGs) têm desempenhado um papel importante no desenvolvimento e na implementação de metodologias e estratégias no campo da educação ambiental. As inovações e ousadias que emergem de profissionais de ONGs são muitas e o que as motiva varia, mas alguns pontos podem ser observados com certa constância. Por exemplo, muitas desenvolvem trabalhos práticos e comumente direcionados a responderem questões emergenciais como: conservação de áreas naturais e espécies ameaçadas de extinção; busca de alternativas sustentáveis para comunidades sem acesso a fontes que poderiam melhorar sua qualidade de vida; proteção de mananciais e cursos d'água; preocupação com o uso inadequado dos recursos naturais; além de temáticas comuns em ambientes urbanos, como acúmulo de lixo, poluição do ar e ineficiência em práticas de reciclagem. Essas podem ser apenas algumas das temáticas abordadas no cardápio de projetos de educação ambiental desenvolvidos por ONGs. Muitas começam sua atuação enfocando temas específicos, mas acabam incluindo outros no percurso de suas ações, porque percebem a interligação entre diferentes questões sociais, e entre estas e suas interfaces com o meio ambiente. $\mathrm{Na}$ ampliação de seus leques de atuação, alguns programas de educação ambiental chegam a perder o foco inicial e por vezes a eficiência em responderem às questões específicas a que se propuseram em sua origem. Todavia, quando são tomados os devidos cuidados, os programas que adotam olhares mais abrangentes podem apresentar maior riqueza, eficácia e consistência nos resultados alcançados, inclusive no tocante às suas propostas originais.

Outra característica das ONGs ligadas à educação ambiental é que ousam trilhar caminhos diferentes e acabam desenvolvendo metodologias que se mostram eficazes e, muitas vezes, possíveis de serem replicadas. A urgência das questões com as quais trabalham serve como fator motivador para a busca de respostas rápidas e consistentes. Diferentemente de outros ambientes de trabalho, muitas experimentam sem receio de crítica, uma vez que os erros podem ser meios de aprendizagem. 
Principalmente entre as ONGs que adotam estratégias de avaliação durante a execução de seus programas, as falhas passam a ser mais facilmente identificadas, o que propicia a percepção dos pontos que necessitam de ajustes. Aumentam, assim, as chances de se atingir mais eficácia do programa como um todo, facilitando a reflexão sobre os caminhos ou metodologias que contribuem para os resultados alcançados.

Outro aspecto relevante e comum às ONGs é a continuidade. Observa-se que muitas desenvolvem trabalhos nas mesmas localidades por longos períodos de tempo, com as temáticas socioambientais que as motivaram a iniciar seus projetos ou programas. O fator continuidade é decisivo em qualquer processo educativo, pois a troca de conhecimentos e a reflexão sobre os valores a serem incorporados podem levar tempo até que se alcance o fortalecimento necessário das pessoas envolvidas para o exercício pleno da cidadania.

\section{O Caso do IPE - Instituto de Pesquisas Ecológicas}

O IPE - Instituto de Pesquisas Ecológicas, uma organização não governamental (ONG) sem fins lucrativos, tem por objetivo trabalhar pela conservação da biodiversidade e pelo desenvolvimento sustentável. Nasceu de apenas um projeto de pesquisa biológica com o mico-leão-preto (Leontopithecus chrysopygus) e seu habitat, a Mata Atlântica do Interior, no oeste de São Paulo, região conhecida como Pontal do Paranapanema, no início da década de 80 (VALLADARES-PADUA, PADUA e CULLEN JR., 2002).

O Pontal sempre foi caracterizado por conflitos pela terra, o que levou Fernando Costa, o governador do Estado no início da década de 40, a tornar a região do oeste de São Paulo uma área protegida de porte considerável: a Grande Reserva do Pontal (FERRARI LEITE, 1998). Seus quase 300 mil hectares nunca chegaram a ser efetivamente protegidos, o que ameaçou de extinção diversas espécies encontradas originalmente no ecossistema local, a Mata Atlântica de Interior. Uma série de invasões e conflitos marcou a história do Pontal e o resultado foi a perda de aproximadamente 240 mil hectares de matas, sobrando apenas o Parque Estadual do Morro do Diabo, administrado pelo 
Instituto Florestal de São Paulo, com 36 mil hectares, e o restante constituído de fragmentos espalhados pela região (FERRARI LEITE, 1998; VALLADARES-PADUA, PADUA e CULLEN JR., 2002; PADUA E SÁ, 2007).

Nesse cenário, os pesquisadores que iniciaram o projeto com o mico-leão-preto perceberam a complexidade das questões relacionadas à conservação e a necessidade de envolver as comunidades locais por meio da educação ambiental e, posteriormente, do desenvolvimento sustentável (PADUA E SÁ, 2007). Muitos projetos passaram a ser concebidos de maneira a complementar um programa integrado, sendo a educação ambiental uma ponte entre as questões ambientais e as sociais. O objetivo tem sido disseminar o conhecimento adquirido em campo, de modo a sensibilizar a população que vive no entorno de áreas naturais para a importância da natureza e dos benefícios que a convivência harmônica ser humano/natureza pode proporcionar. Gradativamente, as pressões contínuas sobre o ambiente natural vêm sendo trabalhadas com públicos bem diversos, inclusive as famílias do Movimento dos Trabalhadores Rurais Sem Terra (MST) que chegaram maciçamente à região em meados da década e 90 (VALLADARES-PADUA, PADUA e CULLEN JR, 2002).

$O$ fator motivador inicial do programa de educação ambiental do IPÊ no Pontal foi buscar o envolvimento de públicos diversos, desde alunos e professores até proprietários de terras, tomadores de decisão e membros da comunidade local para a questão das riquezas naturais remanescentes e a necessidade de se protegê-las melhor. Com a vivência na região, ficou claro para o grupo de pesquisadores que os ecossistemas naturais necessitavam de atenção e de ação direta, além de medidas de proteção, como a recuperação de áreas degradadas ou a ampliação de extensões florestadas. Foi assim que surgiram projetos de criação de viveiros de espécies nativas e o plantio de árvores com finalidades diversas (corredores de matas, zonas 'tampão', pequenos bosques ou 'trampolins ecológicos'), além de produtos orgânicos, como café e buchas, plantados à sombra de árvores também plantadas pelos agricultores com a orientação da equipe do IPÊ. Nasceu, assim, juntamente com uma educação ambiental mais abrangente, um programa de alternativas sustentáveis de desenvolvimento para os pequenos proprietários rurais da região, cuja maioria é de 
assentados. Hoje, mais de 450 famílias trabalham juntamente com o IPE em projetos dessa natureza, o que tem ajudado a "esverdear" a região e a trazer uma nova consciência sobre a importância de se integrar aspectos sociais aos ambientais e vice-versa (PADUA e SÁ, 2007; VALLADARES-PADUA, PADUA e CULLEN JR., 2002).

O envolvimento da população local passou, então, a ser uma das prioridades do programa de conservação do IPE. Esse envolvimento inclui a participação de todos os segmentos sociais, desde prefeito, demais autoridades e tomadores de decisão até educadores, comerciantes e moradores da cidade de Teodoro Sampaio e das áreas adjacentes ao Parque Estadual do Morro do Diabo e fragmentos florestais de maior porte. Portanto, o programa de educação ambiental foi desenvolvido inicialmente para o público escolar e para ajudar a proteger uma espécie e seu habitat. Mas, com as perdas aceleradas das áreas naturais e a compreensão dos educadores do IPE da importância de se envolver os adultos nos processos educativos para que as chances da conservação efetiva da natureza local fossem maiores, houve uma ampliação dos objetivos a serem alcançados. Os adultos tornaram-se um públicoalvo importante a ser sensibilizado e estratégias educativas foram criadas e implementadas para envolver as comunidades locais e os tomadores de decisão, de modo que se definisse conscientemente o destino dos remanescentes naturais com princípios éticos e inclusivos (PADUA, 1997, p. 2001).

O objetivo do programa educacional do IPE sempre foi disseminar informações sobre a natureza e a importância de se proteger os remanescentes florestais, aumentando a auto-estima e o orgulho da população local em relação às riquezas naturais ali encontradas. As estratégias educacionais incluem uma variedade de abordagens, dependendo do público a que se dirigem, mas compreendem palestras, debates e exposições, além de reuniões participativas, as Eco-Negociações, que promovem o encontro de diversos segmentos sociais para a troca de idéias e para a elaboração de ações a serem desenvolvidas localmente (PADUA et al, 2006). Nesse processo, há um fortalecimento de pessoas e grupos locais que percebem a importância de cada um fazer sua parte para a transformação das realidades indesejadas, encorajando todos a assumirem compromissos ligados à conservação e à melhoria de vida, sempre tendo como pano de fundo a conexão ser 
humano/natureza (PADUA, 2004; PADUA et al, 2006; VALLADARES-PADUA, PADUA e CULLEN JR., 2002).

Como pode ser observado na Figura 1, o modelo de conservação desenvolvido pelo IPE mostra a evolução da perspectiva inicial do projeto, ampliada a partir do foco em uma espécie, abrangendo outras dimensões da realidade local. A equipe envolvida passou a ser cada vez mais interdisciplinar e a atuar de maneira integrada, de modo a enriquecer o resultado de cada projeto e do programa como um todo.

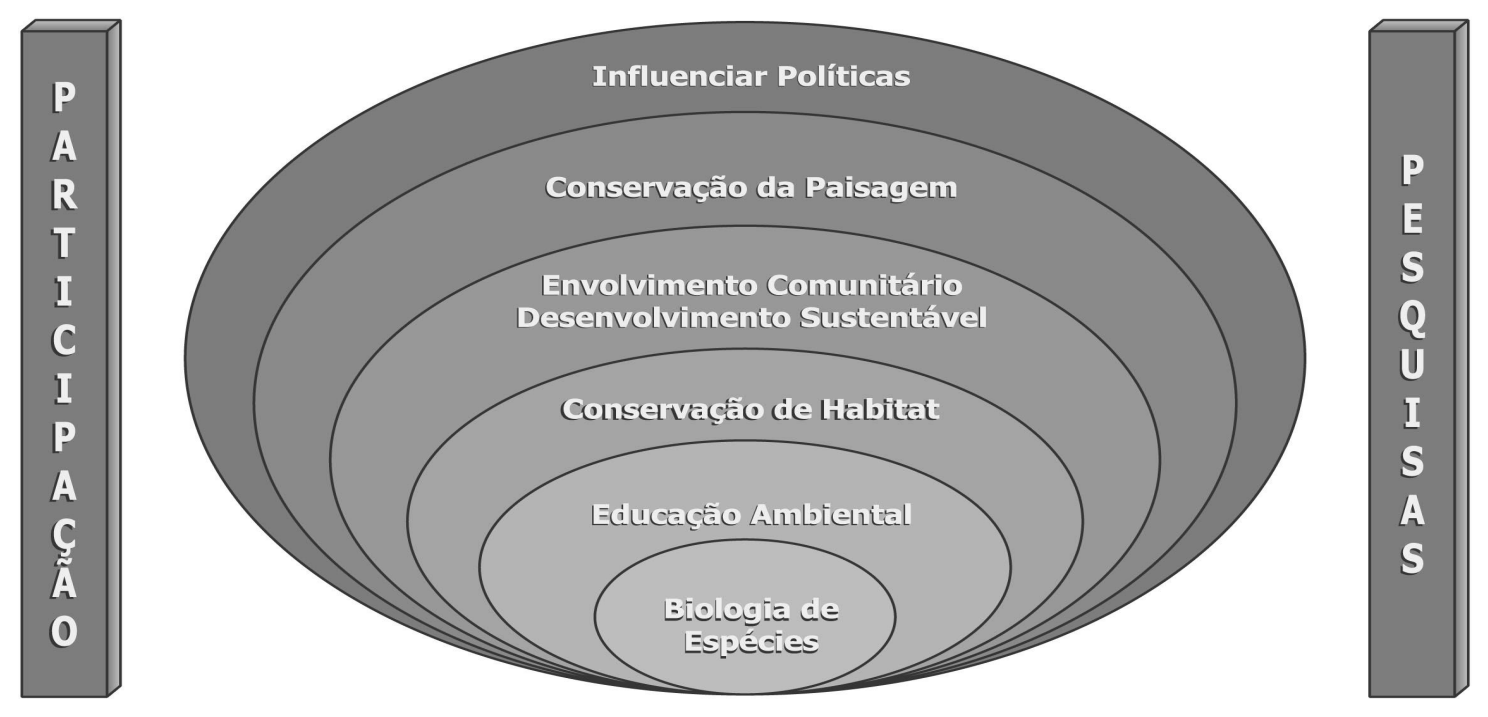

Figura 1 - Ilustração do modelo interdisciplinar de Valladares-Padua, Padua e Cullen Jr. (2002); Padua e Sá (2007).

O estudo inicial parte de pesquisas com espécies, em geral ameaçadas, de modo a conhecer as necessidades de conservação e ao mesmo tempo torná-las símbolos de orgulho para os moradores locais. O conhecimento adquirido nos trabalhos de campo é transmitido em linguagem acessível por meio de estratégias educacionais variadas.

A educação ambiental propicia também o engajamento das pessoas nos processos de transformação sociais e ambientais, pois muitos percebem o papel que podem desempenhar como participantes de mudanças que beneficiem a coletividade. As ações guiadas pelo conhecimento científico têm maiores chances de contribuir de maneira significativa para a conservação de espécies e 
ecossistemas e para o desenvolvimento de alternativas sustentáveis para as populações locais.

Experiências bem sucedidas passam a ser chave para mostrar que a natureza e a melhoria das condições de vida humana são complementares. Isso tem sido possível com práticas ligadas à própria natureza, em geral com projetos agroflorestais e artesanatos que enfocam as espécies encontradas na região.

Influenciar políticas públicas nem sempre é fácil. Todavia, a participação local e regional se torna fundamental para que as pessoas percebam seu papel de cidadãos e o valor de se organizarem coletivamente (PADUA, 2004). As Eco-Negociações, ou fóruns participativos promovidos a cada dois anos, têm contribuído para o fortalecimento de pessoas e grupos que se formam a partir de objetivos comuns, muitas vezes influenciando políticas públicas (PADUA et al, 2006).

No início de sua existência, o IPÊ tinha como propósito maior a conservação de espécies e ecossistemas. Gradativamente, houve uma transformação interna e um amadurecimento da equipe, que percebeu a necessidade de incluir áreas diferentes do saber e do agir. Os educadores ambientais conquistaram espaço e, aos poucos, mostraram o efeito de se trabalhar de maneira abrangente $\mathrm{e}$ inclusiva. A educação ambiental tornou-se a ponte entre os diferentes interesses e proporcionou a sinergia necessária para se fortalecer os projetos em andamento, tornando-os parte de programas integrados.

Com o aumento de apoio à conservação por parte do público externo, intensificou-se também o respeito dos pesquisadores do próprio IPÊ pelo campo da educação ambiental. Houve, assim, uma conquista de credibilidade dentro da instituição, e hoje não há qualquer questionamento quanto à sua importância. Coube à educação ambiental integrar os aspectos socioambientais, cada vez mais evidenciados e percebidos como fundamentais para que a conservação ocorresse com maior efetividade (PADUA, 2004; PADUA e SÁ, 2007).

Sendo assim, os pesquisadores passaram a dar maior apoio aos programas e a se disponibilizar a compartilhar os 
conhecimentos adquiridos em seus estudos de campo. Passaram, também, a compreender a importância de se integrar aspectos sociais, como desenvolvimento sustentável para os moradores locais, em seus projetos de pesquisa. Ao assumirem pessoalmente o papel de educadores, os pesquisadores se percebem como educadores e educandos ao mesmo tempo, efetivando o princípio proposto por Paulo Freire (1979), segundo o qual todos somos professores e aprendizes em constante troca.

O fato de a educação ambiental adotar métodos científicos em seus programas ajudou a conquistar credibilidade 'científica' internamente. Muitos estudos foram realizados utilizando-se desenhos experimentais e avaliações quali-quantitativas (PADUA, 1997). Mas também tem sido utilizada a pesquisa-ação, que, como propõe Vasconcelos (1998, p. 263), "parte do diálogo entre a ciência e o senso comum", passou a ser mais bem compreendida a partir da realização das Eco-Negociações e dos resultados que emergiram desses fóruns participativos (PADUA et al, 2006). Vasconcelos ainda descreveu desafios dessa linha de pesquisa, que se aplicam a uma instituição como o IPÊ, quando explica: "Enfrenta por isso problemas relacionados à ciência, ao conhecimento comum, às relações entre pessoas e ao tipo de transformações ocorridas" (1998, p. 263-264). Entre a equipe do IPE $\hat{E}$, houve, no início, desconfiança e questionamento se o esforço para se realizar programas de interação dos diversos atores sociais fazia parte da missão institucional e se os estudos que adviriam de tais iniciativas poderiam ser considerados 'ciência'. Aos poucos, no entanto, mesmo os pesquisadores mais tradicionais perceberam o valor da integração das pessoas nos projetos de cunho conservaconista e o poder de se disseminar valores que integram gente e natureza (PADUA, 2004; PADUA e SÁ, 2007).

A metodologia desenvolvida pelo IPE para integrar os diversos segmentos sociais às questões socioambientais parte da compreensão da importância de se trabalhar os dois lados do cérebro, e não somente o racional e lógico. Essa abordagem ajudou a mostrar a eficácia das iniciativas participativas, como é o caso das Eco-Negociações (PADUA et al, 2006). Portanto, a abordagem 
participativa compreende o ser humano de forma integral, fazendo uso de ambos os lados do cérebro, conforme Barbier (1998) sugere, sendo o direito conhecido como cérebro artístico e o esquerdo responsável pelo pensamento discriminatório mais acentuado. Por um lado, inclui racionalidade e capacidade de estrutura organizacional e, por outro, sensibilidade e intuição, que envolvem valores.

Para Barbier (1998), no processo participativo é fundamental o que ele chama de "escuta sensível", que ocorre em vários níveis e depende de uma atenção plena e receptiva. Por exemplo, a escuta científica apóia-se na criação de metodologias que levam à ação e à pesquisa, o que é de grande importância para a educação dado o seu papel transformador. A escuta poética inclui a atenção aos fenômenos imprevistos e demanda sensibilidade e abertura por parte do pesquisador. Finalmente, a escuta espiritual ou filosófica está relacionada aos valores que regem o ser humano, exigindo do cientista a capacidade de enxergar pelos olhos dos outros. A pesquisa-ação que Barbier (1996) propõe compreende os três olhares ao mesmo tempo, sendo um complementar ao outro. Com essa abertura, a pessoa passa a escutar a si mesma, o outro, os outros e o mundo, pois percebe a complexidade ao seu redor.

Outro princípio adotado pelo IPE foi proposto por Buber (1974) e tem sua base na relação 'Eu/Tu', na qual o respeito e a alteridade são a tônica. Ao invés de se querer impor idéias e de se objetivar homogeneizar o pensamento das pessoas, inclui-se as diferenças e celebra-se a diversidade cultural e de idéias. Dessa forma, todos são incluídos e se tornam participantes das mudanças almejadas. Quando a prática desse tipo de relação se torna constante, é possível expandir do individual para o coletivo, priorizando temáticas que visavam beneficiar a sociedade e a natureza, passando do contato pessoa/pessoa às relações cada vez mais grupais.

Essa têm sido uma das bases conceituais adotadas pelo IPE no desenvolvimento da abordagem participativa ao longo do tempo, com aplicação nos mais diversos contextos de atuação. Apesar de não ter intenção de ser linear, suas etapas podem ser analisadas na Tabela 1. 
Tabela 1 Abordagem participativa utilizada na construção conjunta de novas realidades socioambientais.

\begin{tabular}{|c|c|c|}
\hline & Etapas do Processo & Valores Correspondentes \\
\hline A & $\begin{array}{l}\text { 6. Acompanhamento } \\
\text { - modificar estratégias } \\
\text { - disseminar resultados }\end{array}$ & $\begin{array}{l}\text { Flexibilidade } \\
\text { Altruísmo } \\
\text { Transformação }\end{array}$ \\
\hline V & - obter apoio & Renovação \\
\hline A & 5. Parcerias & $\begin{array}{l}\text { Solidariedade } \\
\text { Cooperação }\end{array}$ \\
\hline $\mathrm{L}$ & $\begin{array}{l}\text { 4. Desenvolvimento de estratégias } \\
\text { - buscar recursos locais - } \\
\text { humanos ambientais e materiais }\end{array}$ & $\begin{array}{l}\text { Humildade } \\
\text { Entusiasmo } \\
\text { Ousadia }\end{array}$ \\
\hline $\mathrm{I}$ & $\begin{array}{l}\text { - trazer inputs externos - humanos, } \\
\text { ambientais e materiais }\end{array}$ & Persistência \\
\hline A & $\begin{array}{l}\text { 3. Sonho ou visão } \\
\text { - formular objetivos e metas }\end{array}$ & $\begin{array}{l}\text { Criatividade } \\
\text { Intuição } \\
\text { Afetividade }\end{array}$ \\
\hline$\tilde{\mathrm{A}}$ & $\begin{array}{l}\text { 2. Reflexão sobre potenciais locais } \\
\text { - trocar idéias, experiências e } \\
\text { conhecimentos }\end{array}$ & $\begin{array}{l}\text { Auto-estima } \\
\text { Orgulho }\end{array}$ \\
\hline $\mathrm{O}$ & $\begin{array}{l}\text { 1. Identificação de problemas } \\
\text { e temas }\end{array}$ & $\begin{array}{l}\text { Respeito } \\
\text { Empatia } \\
\text { Receptividade }\end{array}$ \\
\hline
\end{tabular}

Baseado em Padua; Tabanez; Souza e Hoefel (1999) e Padua (2001).

As etapas podem ser compreendidas conforme as explicações que se seguem:

1. A identificação dos problemas ou temas a serem trabalhados reflete as expectativas e as necessidades da população, razão da importância da participação dos diversos segmentos sociais em todo o processo. Pessoas externas são capazes de trazer experiências de outras realidades e os pesquisadores enriquecem a troca de idéias com informações pertinentes às realidades locais. Mas, quando a sociedade local busca suas próprias soluções e meios de implementar o que considera prioritário, a responsabilidade passa a ser de todos e valores como respeito, empatia e receptividade são cruciais para a construção de novas realidades que reflitam os anseios de todos. 
2. A reflexão sobre os potenciais e as riquezas locais - inclui aspectos humanos, culturais e ecológicos. Nesta etapa, trabalha-se a auto-estima e o orgulho, que comumente são baixos em comunidades rurais ou em regiões afastadas dos grandes centros, já que raramente exercem o papel de agentes de mudanças. A valorização de aspectos locais, como espécies raras e endêmicas, elementos naturais, tradições culturais como festas folclóricas, costumes, arte, entre outros, pode despertar a autoconfiança, ajudando o indivíduo a acreditar em sua própria capacidade de agir em prol de um ideal. Do processo de motivação individual pode desencadear um interesse coletivo, ampliando as chances de mudanças e promovendo posturas éticas de todos os envolvidos.

3. A idealização ou sonho, ou a definição dos objetivos a serem alcançados - depende de um exercício de visualizar a solução ideal para os problemas identificados. Nesta etapa, as pessoas identificam seus sonhos, que passam a ser o ponto de partida para trilhar os caminhos a serem percorridos. Esta fase estimula a criatividade, a intuição e a afetividade, elementos que podem contribuir para inspirar situações ideais.

4. O desenvolvimento de estratégias - só é possível quando se sabe onde se quer chegar e por isso só deve ser definido após as três fases anteriores terem sido alcançadas. Os sonhos servem de base para se identificar o que pode ser implantado em direção ao alcance dos objetivos desejados e quais os passos que levam dos problemas às situações ideais, preferencialmente a partir das potencialidades locais. Os valores correspondentes a esta fase compreendem humildade, entusiasmo, ousadia e persistência, podendo a responsabilidade de implantar as estratégias definidas ser assumida individual ou coletivamente, dependendo do processo de criação e do grau de interesse dos participantes.

5. A busca de parcerias - visa fortalecer as propostas e as possibilidades de implantação das estratégias criadas. Quando essas parcerias são locais, aumenta-se a valorização do que é regional e os agentes de mudança podem também sentir-se participantes e fortalecidos por serem parte das soluções propostas. A solidariedade e a cooperação são os valores mais preponderantes 
nesta etapa, e uma atenção especial deve ser dada para se evitar a dependência em lideranças ou do controle de determinados indivíduos ou instituições sobre outros.

6. Avaliação e acompanhamento - são fundamentais para se refletir sobre os processos percorridos, facilitando ajustes e melhorias no decorrer da implantação das estratégias criadas. Evitam que se descubra somente após serem implementadas que algumas estratégias não produziram efeitos. Permitem, assim, detectar falhas, evitando desperdícios de tempo, energia e recursos. As informações oriundas de avaliações podem também ser úteis para se obter recursos, disseminar resultados e retro-alimentar os envolvidos. Quando os participantes observam quais os aspectos bem sucedidos e quais necessitam de mudanças, lidam com flexibilidade, altruísmo, poder de transformação e de renovação, além de humildade, pois há sempre a possibilidade de se descobrir que os resultados não foram tão eficazes quanto se esperava.

Mesmo tendo sido concebida para o Pontal do Paranapanema, esta abordagem já foi adotada com sucesso nos diversos contextos em que o IPE atua. Não se trata de uma receita com etapas rigidamente preestabelecidas, uma vez que é a própria comunidade que identifica os passos a serem dados. Os resultados alcançados refletem, assim, os diferentes anseios e o perfil cultural das diferentes realidades onde se está inserido.

\section{Conclusões}

O Pontal do Paranapanema vem sendo uma grande escola para o IPE. As lições aprendidas e as metodologias desenvolvidas têm sido adaptadas a outros contextos nos quais a instituição atua, naturalmente com os devidos ajustes que se fazem necessários. É importante ressaltar a importância de se levar em conta as características culturas locais, assim como os ecossistemas e suas necessidades. O respeito serve de base para o diálogo e a convivência entre os diferentes atores sociais.

Outro aspecto relevante é a transparência. Nos processos participativos que o IPÊ promove, a instituição expressa suas idéias e expectativas como mais um ator em meio aos demais. Não há o incentivo a pessoas ou grupos se tornem predominantes sobre 
outros, pois a idéia é quebrar tendências 'coronelistas', comuns no interior do Brasil. A abordagem apresentada é, em sua essência, inclusiva e 'empoderadora' e, por isso, visa a participação de todos.

Esta tem sido a base do trabalho educativo do IPE, que visa propiciar uma convivência harmônica entre ser humano e natureza. O diálogo com o outro é facilitado e enriquecido conforme os princípios propostos por Buber (1874), nos quais há o predomínio do $\mathrm{Eu} / \mathrm{Tu}$ em qualquer circunstância, principalmente quando as divergências se fazem presentes. $O$ que se espera em mais longo prazo, e que tem sido alcançado em diversas regiões onde o IPE atua, principalmente no Pontal do Paranapanema, é que das relações concebidas com os princípios 'Eu/Tu' haja uma gradativa extensão ao 'Nós/Vocês', possível quando a qualidade de respeito pelas diferenças passa, no mínimo, a coexistir com os conflitos socioambientais.

\section{Referências bibliográficas}

BARBIER, R. A Pesquisa-ação. Tradução de Lucie Didio. Porto Alegre: UFRS, 1996 (documento mimeografado).

A escuta sensível na abordagem transversal. In: BARBOSA, J.G. Multirreferencialidade nas ciências e na educação. São Carlos: EdUFSCar, 1998.

BUBER, M. Eu e Tu. São Paulo: Centauro Editora, 1974.

FERRARI LEITE, J.A. Ocupação do Pontal do Paranapanema. São Paulo: Editora Hucitec, 1998.

FREIRE, P. Educação e mudança. São Paulo: Editora Paz e Terra, 1979.

PADUA, S. Uma pesquisa em educação ambiental: a conservação do mico-leãopreto (Leontopithecus chrysopygus). In: VALLADARES-PADUA, C. e BODMER, R. (Orgs.). Manejo e conservação de vida silvestre no Brasil. Brasília: MCT CNPq e Sociedade Civil Mamirauá, 1997, p. 34-42.

- Educação Ambiental e Participação Comunitária: chaves para a conservação da biodiversidade. In: ROURE, M. e PADUA, S. (Orgs.). Empreendedores sociais em ação. São Paulo: Cultura Editores, 2001, p. 183-201. 
; TABANEZ, M.; SOUZA, M.G. e HOEFFEL, J.L. Participação: Um elemento-chave para envolvimento comunitário - Uma experiência em Educação Ambiental na Área de Proteção Ambiental - APA Piracicaba. Revista Educação e Ensino. Usf, Bragança Paulista, SP, v. 4, n. 2, p. 75-84, 1999.

; SÁ, L.; SOUZA, M.G. e TABANEZ, M. Herramientas de integración socioambiental em uma región de conflicto. Tópicos en Educación Ambiental, 5 (14), p. 8-22, 2006.

e SÁ, L.. A influência da educação ambiental na região do Pontal do Paranapanema e no Instituto de Pesquisas Ecológicas (IPÊ). In: JUNQUEIRA, V. e NEIMAN, Z. (Ed.). Educação Ambiental e Conservação da Biodiversidade. 2007, p. 121-138.

VALLADARES-PADUA, C., PADUA, S. e CULLEN L. Within and surrounding the Morro do Diabo State Park, São Paulo: biological value, conflicts mitigation and sustainable development alternatives. Environmental Science and Policy, Grã-Bretanha, 2002. v. 5, n. 1, p. 69-78.

VASCONCELLOS, H. A pesquisa-ação em projetos de educação ambiental. In: PEDRINI, A. (Org.). Educação ambiental: reflexões e práticas contemporâneas. Petrópolis: Editora Vozes, 1998, p. 260-289. 